\title{
Efficacy and Safety of Avatrombopag in Patients with Chronic Immune Thrombocytopenia: A Systematic Literature Review and Network Meta- Analysis
}

Piotr Wojciechowski · Koo Wilson · Jameel Nazir · Iwona Pustułka •

Anna Tytuła · Beata Smela · Michał Pochopien · Michael Vredenburg •

Keith R. McCrae $\cdot$ Wojciech Jurczak

Received: February 26, 2021 / Accepted: April 18, 2021 / Published online: May 1, 2021

(c) The Author(s) 2021

\section{ABSTRACT}

Introduction: A network meta-analysis (NMA) was performed to assess the efficacy and safety of avatrombopag, relative to eltrombopag, romiplostim, and fostamatinib, for patients with chronic immune thrombocytopenia (ITP) not responding adequately to corticosteroids.

Methods: A systematic search of publication and clinical trial databases was conducted to identify relevant randomized controlled trials

Keith R. McCrae and Wojciech Jurczak are senior authors and contributed equally to this work.

Supplementary Information The online version contains supplementary material available at https:// doi.org/10.1007/s12325-021-01752-4.

P. Wojciechowski $(\bowtie) \cdot$ I. Pustułka · A. Tytuła B. Smela $\cdot$ M. Pochopien

Creativ-Ceutical, Creativ-Ceutical Poland Sp. z o.o., Ul. Przemysłowa 12, 30-701 Krakow, Poland

e-mail: Piotr.Wojciechowski@creativ-ceutical.com

K. Wilson · J. Nazir

Swedish Orphan Biovitrum AB, Stockholm, Sweden

M. Vredenburg

Dova Pharmaceuticals, Durham, NC, USA

K. R. McCrae

Taussig Cancer Institute, Cleveland Clinic,

Cleveland, OH, USA

W. Jurczak

National Research Institute of Oncology, Kraków, Poland
(RCTs) and observational studies. Data from eligible studies were extracted and analyzed in a Bayesian framework using relative effect sizes vs placebo. Outcomes included durable platelet response; need for rescue therapy; reduction in use of concomitant ITP medication; incidence of any or World Health Organization (WHO) grade $2-4$ bleeding events, and any adverse events. Results were reported as odds ratios or incidence rate ratios (IRR) with 95\% credible intervals (CrIs).

Results: The NMA included seven phase 3 RCTs. Compared with placebo, avatrombopag was associated with statistically significant improvements in durable platelet response, reduction in use of concomitant ITP medication, and incidence of any bleeding events. Statistically significant differences vs placebo were also observed for durable platelet response and need for rescue therapy (eltrombopag, romiplostim, and fostamatinib); reduction in use of concomitant ITP medication (eltrombopag and romiplostim); incidence of any bleeding events (fostamatinib); and incidence of WHO grade 2-4 bleeding events (romiplostim and fostamatinib). No statistically significant differences were observed for any adverse events. Avatrombopag was associated with a statistically significant lower incidence of any bleeding events vs eltrombopag (IRR 0.38 [95\% CrI 0.19, 0.75]) and romiplostim (IRR 0.38 [95\% Crl 0.17, 0.86]); no other between-treatment differences were observed. 
Conclusion: In this NMA, avatrombopag significantly increased the chance of achieving durable platelet response and reducing the use of concomitant ITP medication vs placebo, and significantly reduced the incidence of any bleeding events compared with placebo, eltrombopag, and romiplostim. The study aims to help guide clinicians managing patients with chronic ITP and insufficient response to previous treatment.

Keywords: Avatrombopag; Chronic immune thrombocytopenia; Eltrombopag; Fostamatinib; Network meta-analysis; Platelets; Romiplostim

\section{Key Summary Points}

Why carry out this study?

Second-line treatment strategies approved for the treatment of chronic immune thrombocytopenia in patients who have not responded adequately to corticosteroids include thrombopoietin receptor agonists avatrombopag, eltrombopag, and romiplostim, and the spleen tyrosine kinase inhibitor fostamatinib

Avatrombopag is the newest of these agents approved for the treatment of chronic immune thrombocytopenia in Europe and the USA; however, there are limited head-to-head study data available

What did the study ask?/What was the hypothesis of the study?

A network meta-analysis (a type of indirect treatment comparison) was performed to assess the efficacy and safety of avatrombopag relative to eltrombopag, romiplostim, and fostamatinib, determined using relative effect sizes vs placebo

\section{What were the study outcomes/conclusions?}

Avatrombopag is associated with a greater chance of durable response, reduced use of concomitant immune thrombocytopenia treatments and less frequent bleeding than placebo; and may be associated with a significantly reduced rate of any bleeding events than eltrombopag and romiplostim

\section{What has been learned from the study?}

Avatrombopag is an effective and welltolerated treatment for patients with chronic immune thrombocytopenia

This analysis adds to the limited evidence base for this condition and may ultimately help to guide clinicians managing patients with chronic immune thrombocytopenia

\section{DIGITAL FEATURES}

This article is published with digital features, including a summary slide, to facilitate understanding of the article. To view digital features for this article go to https://doi.org/10.6084/ m9.figshare.14438741.

\section{INTRODUCTION}

Immune thrombocytopenia (ITP) is an autoimmune hematologic disorder leading to thrombocytopenia (below $100 \times 10^{9} / \mathrm{L}$ ) as a consequence of platelet destruction and insufficient platelet production [1-3]. Bleeding diathesis is the most common clinical manifestation of ITP [4], associated with substantial morbidity and mortality, particularly in severe cases with platelet counts below $20-30 \times 10^{9} / \mathrm{L}$ $[2,3]$. Approximately $80 \%$ of patients with ITP have primary (idiopathic) disease, while the remaining cases are secondary to autoimmune diseases, viral infections, specific drugs, or vaccinations [3]. To enable alignment of research 
studies and ultimately aid management of this condition, in 2009, an international working group (IWG) published recommendations for standardizing ITP-associated definitions and terminology. This included defining three disease phases of "newly diagnosed", "persistent", and "chronic" with durations of less than 3 months, 3-12 months, and more than 12 months, respectively [5].

Clinical guidelines recommend that treatment is initiated in patients with bleeding diathesis and all asymptomatic cases with platelet counts below $30 \times 10^{9} / \mathrm{L}$, aiming to improve platelet count and achieve hemostasis $[6,7]$. Treatment should be tailored, considering factors such as patient lifestyle and therapeutic preferences [6, 7]. The mainstay of first-line treatment is corticosteroids; however, intravenous immunoglobulin (IVIG) and anti-D immune globulin, may also be considered $[3,6,7]$. With most adults (50-80\%) progressing to chronic ITP (cITP) [4, 8], these agents frequently fail to achieve durable remission, and additional therapeutic options are required. This manuscript focuses on this adult patient population, and the available second-line treatments following failure of corticosteroids and IVIG.

Second-line treatment strategies approved for the treatment of ITP in patients who have not responded adequately to corticosteroids include thrombopoietin receptor agonists (TPORAs), e.g., avatrombopag, eltrombopag, and romiplostim, and the spleen tyrosine kinase inhibitor fostamatinib [9-12]. Overall, TPO-RAs have high clinical response rates and are generally well tolerated; however, over time, a proportion of patients stop benefiting from the initial TPO-RA they are prescribed and are required to switch to an alternative TPO-RA [13]. Over $75 \%$ of patients achieve or maintain a response after a switch [13], including those who became resistant to the first TPO-RA. Second-line treatment options also include off-label use of rituximab and splenectomy, which is now used less frequently as other therapeutic options have emerged [14].

cITP is a rare disease (1.6-3.2 per 100,000 adults) $[4,15]$, which is reflected by very limited availability of clinical evidence [6].
Avatrombopag is the newest agent approved for the treatment of cITP in Europe and the USA $[10,16]$. Head-to-head studies comparing the efficacy and/or safety of avatrombopag with other treatments in cITP are limited. A head-tohead study of avatrombopag vs eltrombopag was initiated but terminated early (because of enrollment challenges). Consequently, alternative approaches are required to help clinicians decide between the treatment options for cITP. Network meta-analyses (NMAs) are a recognized approach that extends a conventional pairwise meta-analysis to allow the simultaneous comparison of three or more treatments within a single analysis. NMAs use the data within randomized controlled trials (RCTs) to form a network of indirect comparisons across trials using a common comparator (in this instance, placebo).

The present manuscript describes an indirect treatment comparison to assess the efficacy and safety of avatrombopag relative to eltrombopag, romiplostim, and fostamatinib, determined using relative effect sizes vs placebo, in adult patients with cITP and insufficient response to previous therapy.

\section{METHODS}

This study was performed in line with the Preferred Reporting Items for Systematic Review and Meta-Analyses (PRISMA) guidelines [17]. This article is based on previously conducted studies and does not contain any new studies with human participants or animals performed by any of the authors.

\section{Systematic Literature Review}

A systematic literature review was conducted to identify RCTs and observational studies involving adult patients with cITP (at least 12 months' duration, consistent with the 2009 IWG definition [5]), who had been treated with avatrombopag, eltrombopag, romiplostim, or fostamatinib after exhibiting an insufficient response to previous therapy. Literature searches, involving Embase, Medline, the Cochrane Central Register of Controlled Trials 
(CENTRAL), and the Cochrane Database of Systematic Reviews, were conducted in March 2020. ClinicalTrials.gov was also interrogated and additional information was obtained from a UK National Institute for Health and Care Excellence (NICE) appraisal involving eltrombopag [18] and romiplostim [19]. The inclusion/ exclusion criteria are shown in Table S1 in the supplementary material. The search strategy was developed using keywords grouped in domains representative for ITP, respective therapies, and clinical studies combined with appropriate Boolean expressions. Keywords for the clinical evidence were not restricted to RCTs, but also included other studies in order to provide a high level of specificity without compromising sensitivity, as recommended by the Cochrane handbook for systematic literature reviews [20].

To assess risk of bias in the analyzed RCTs, the methodological quality of the studies was assessed using a tool based on guidance for undertaking reviews in healthcare from the Centre for Reviews and Dissemination at the University of York, UK [21].

\section{Network Meta-Analysis}

The NMA allowed a simultaneous comparison of multiple treatments (up to four plus placebo in this case), some of which were not directly compared in RCTs. Table 1 provides details of the inclusion and exclusion criteria for the NMA used to select homogeneous clinical data representative of the target population. Notably, cITP is currently defined using a duration of at least 12 months [5]. Although the pivotal trial assessing avatrombopag used this definition, some trials may have been designed and conducted before the current definition was developed, recruiting patients with disease lasting at least 6 months. Consequently, inclusion criteria were relaxed for comparator trials to include studies enrolling patients with shorter disease duration, provided that the study met all the other inclusion criteria for the NMA. In addition, only studies describing European Medicines Agency (EMA)-approved dosing regimens were included.
Feasibility and heterogeneity analyses were performed to select the outcomes to be assessed in the NMA on the basis of their clinical relevance.

\section{Data Preparation and Statistical Analysis}

Between-trial heterogeneity was notable for the rate of discontinuation. The proportion of patients who discontinued from the placebo arm was greater than that of the active group in the avatrombopag and fostamatinib studies (Fig. S1 in the supplementary material). In addition, the rates of discontinuation reported in the studies of eltrombopag [23] and romiplostim [24] were considerably lower than those seen in the avatrombopag and fostamatinib studies; the eltrombopag and romiplostim studies had been conducted in a different clinical context, with differing availability of therapeutic alternatives for patients with suboptimal response. This significant and imbalanced discontinuation introduces a high risk of bias. To adjust for this imbalance in discontinuation, the NMA was conducted using estimated incidence rate ratio (IRR) for need for rescue therapy and incidence of any bleeding events, World Health Organization (WHO) grade $2-4$ bleeding events, and any adverse event (AE). IRR is more appropriate for these outcomes because not only does it account for the number of events in the treatment vs placebo arms but it also accounts for the mean exposure time. Thus, IRRs were calculated by dividing the number of patients experiencing the event by the mean exposure time multiplied by the total number of patients. The estimated mean duration of exposure within each study arm was calculated by fitting the exponential survival curve to the reported proportion of patients who discontinued.

The NMA was conducted using a contrastbased approach with a Bayesian framework, which followed NICE guidelines [25], and a Markov chain Monte Carlo method implemented in WinBUGS with vague prior distributions for model parameters. Non-informative prior distributions were used for the model parameters of nuisance parameters, treatment 
Table 1 Network meta-analysis: inclusion and exclusion criteria

\begin{tabular}{|c|c|c|}
\hline PICOS & Inclusion criteria & Exclusion criteria \\
\hline Population & Patients $\geq 18$ years of age at screening with chronic ITP ${ }^{a}$ & $\begin{array}{l}\text { Patients }<18 \text { years of age at screening with } \\
\text { chronic ITP } \\
\text { Studies exclusively in Asian patients }\end{array}$ \\
\hline Intervention & $\begin{array}{l}\text { Studies assessing dose regimens approved by EMA } \\
\text { Avatrombopag (initial dose of } 20 \mathrm{mg} \text { once daily) } \\
\text { Eltrombopag (initial dose of } 50 \mathrm{mg} \text { once daily) } \\
\text { Romiplostim (initial dose of } 1 \mu \mathrm{g} / \mathrm{kg} \text { ) } \\
\text { Fostamatinib (initial dose } 100 \mathrm{mg} \text { twice daily) }\end{array}$ & $\begin{array}{l}\text { Studies assessing dose regimens not approved } \\
\text { by EMA }\end{array}$ \\
\hline Comparator & Placebo or one of the comparators & Other comparators or none \\
\hline Outcome & $\begin{array}{l}\text { Duration of platelet response } \\
\text { Need for rescue treatments for bleeding (referred to as } \\
\text { "rescue therapy") } \\
\text { Reduction in use of concomitant ITP treatments } \\
\text { Bleeding events } \\
\text { Mortality } \\
\text { Adverse events } \\
\text { Total number of AEs } \\
\text { Total number of treatment-related AEs } \\
\text { Total number of serious AEs } \\
\text { Hepatoxicity } \\
\text { Food interactions } \\
\text { Injection interactions }\end{array}$ & $\begin{array}{l}\text { Platelet count and duration of platelet count } \\
\text { Dropouts due to AEs }\end{array}$ \\
\hline Study design & RCTs & $\begin{array}{l}\text { Non-RCTs } \\
\text { Studies with treatment period }<9 \text { weeks }\end{array}$ \\
\hline
\end{tabular}

$A E$ adverse event, EMA European Medicines Agency, ITP immune thrombocytopenia, $N M A$ network meta-analysis, $R C T$ randomized controlled trial

a Chronic ITP is at least 12 months' duration according to the 2009 International Working Group definition [5]; this definition was used for the pivotal trial assessing avatrombopag [22]. However, with this definition, comparisons between avatrombopag and comparators were not considered feasible because of a lack of studies meeting these eligibility criteria. Trials involving other agents may have been designed and conducted before the current definition was developed, recruiting patients with disease lasting at least 6 months. Consequently, inclusion criteria were relaxed for comparator trials to include studies enrolling patients with shorter disease duration, provided that the study met all the other inclusion criteria for the NMA and the average duration of the disease was at least 12 months 
effect parameters (normal distributions with mean 0 and variance $10^{4}$ ), and heterogeneity parameters (uniform distribution between 0 and 5 for between-trial standard deviation) for the Bayesian analysis. The contrast-based approach means that data applied to the NMA is not the absolute effect of each treatment arm of the study, but the contrast between the treatment and placebo arms (expressed as a ratio; e.g., if the event rates in the treatment and placebo arms were $30 \%$ vs $6 \%$, this associated relative risk is 5).

Fixed-effect (FE) and random-effect (RE) models were fitted to the data, with model fit based on deviance information criteria (DIC). Being simpler, with fewer estimable parameters, the FE model was preferred, although the RE model could be selected if the difference in DIC between the two models was greater than 5 points [25]. Three chains were run for each analysis with either 25,000 or 50,000 burn-in iterations for the FE and RE models, respectively, followed by 25,000 iterations. Trace plots were generated for the assessment of convergence (Figs. S2-S7 in the supplementary material). The consistency of the results within closed loops of the network was tested using a modified Bucher's approach, as proposed by NICE, with a $p$ value for heterogeneity of less than 0.05 indicating significant inconsistency [26].

Outcomes were presented as odds ratios (ORs) or IRRs with corresponding 95\% credible intervals (95\% CrI). Forest plots of summary statistics were developed. If the associated 95\% CrI did not include 1.0, ORs and IRRs were regarded as statistically significant. IRRs were used for outcomes susceptible to imbalance from early discontinuation due to lack of efficacy. For each outcome, the probability of ranking the treatments from best to worst was estimated; in addition, the overall cumulative ranking of each treatment was estimated using surface under the cumulative ranking (SUCRA) curves.
Fig. 1 Flow chart of the study selection process. NMA network meta-analysis, RCT randomized controlled trial, SLR systematic literature review. ${ }^{*}$ Information from one study was not available from a full-text article

\section{RESULTS}

\section{Systematic Literature Review}

The literature search identified 1822 publications; after removing duplicates, we screened 1496 publications and subsequently excluded 1288 on the basis of the titles and abstracts. After review of the full text, a further 144 publications were excluded leaving a total of 64 publications that met the inclusion criteria (Fig. 1).

\section{Network Meta-Analysis}

\section{Available Evidence}

Overall, a total of seven RCTs met the inclusion criteria for the NMA (Table 2). All were phase 3 double-blind studies providing evidence for avatrombopag (two RCTs), eltrombopag (one RCT), romiplostim (two RCTs), and fostamatinib (two RCTs). Six of the trials included placebo as a comparator, while AVA-305 was designed to compare avatrombopag vs eltrombopag. Although AVA-305 was discontinued prematurely because of enrollment challenges, data from this study was used to provide additional safety findings for the NMA, in part owing to the limited volume of data on patients meeting the current definition of cITP.

The number of patients (12-135 [active treatment arms]), length of follow-up (24-36 weeks), and median duration of disease (1.6-10.8 years) varied across the trials. The median age and median platelet count at baseline ranged from 41 to 57 years and $14-24 \times 10^{9} / \mathrm{L}$, respectively (Table S2 in the supplementary material). Available evidence provided a connected network that linked all the treatments with placebo as a common comparator, allowing comparisons between all the interventions; however, only one study 


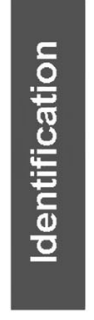

\section{Records identified through database search $(n=1822)$}

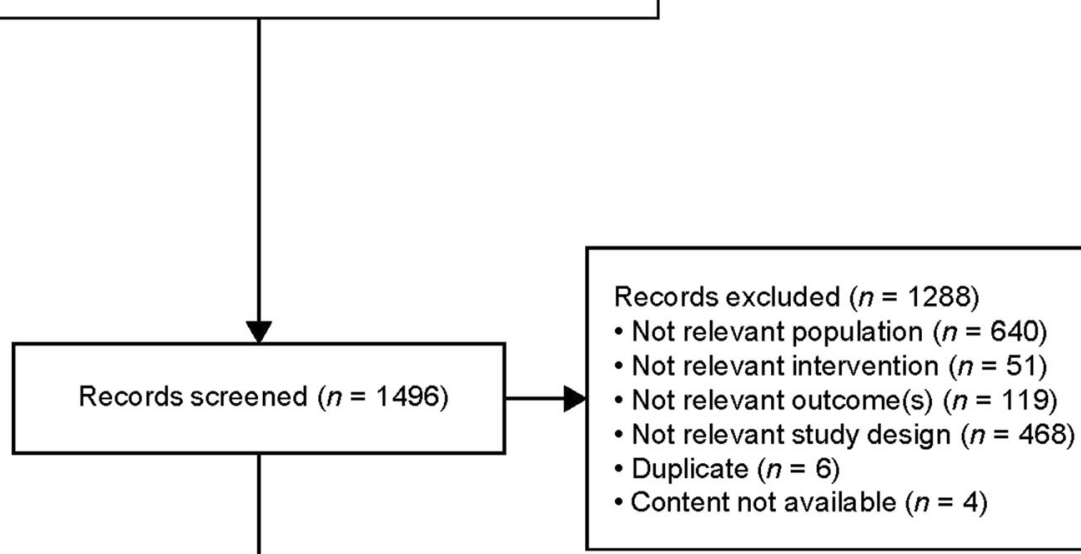

Full-text articles assessed

Full-text articles excluded ( $n=144$ )

- Not relevant population $(n=63)$

- Not relevant intervention $(n=6)$

- Not relevant outcome $(n=15)$

- Not relevant study design $(n=49)$

- Duplicate $(n=11)$

Full-text articles included in the SLR $(n=64)$

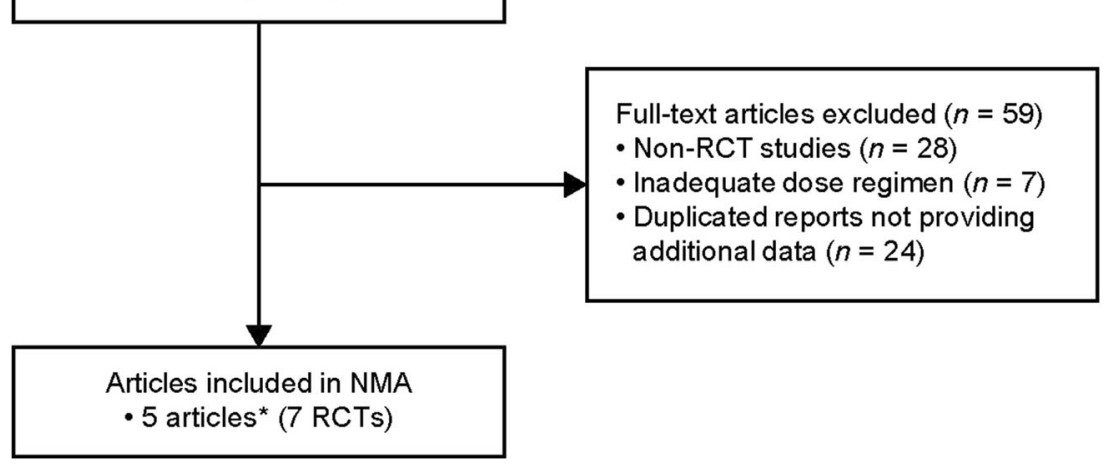


Table 2 Trials included in the network meta-analysis

\begin{tabular}{|c|c|c|c|c|c|}
\hline Study & Design & $\begin{array}{l}\text { Intervention } \\
\text { vs } \\
\text { comparator }\end{array}$ & $\begin{array}{l}\text { Dose } \\
\text { regimens }\end{array}$ & $\begin{array}{l}\text { Length of follow- } \\
\text { up, weeks }\end{array}$ & Primary outcome \\
\hline AVA-302 [22] & $\begin{array}{l}\text { Phase 3, MC, } \\
\text { DB, RCT, } \\
35 \text { centers in } \\
\text { multiple } \\
\text { countries }\end{array}$ & $\begin{array}{l}\text { AVA } \\
\qquad \begin{array}{l}(n=32) \text { vs } \\
\text { PLC } \\
(n=17)\end{array}\end{array}$ & $\begin{array}{r}20 \mathrm{mg} \\
\text { QD }\end{array}$ & 26 & $\begin{array}{l}\text { Number of weeks with } \\
\qquad \mathrm{PC} \geq 50 \times 10^{9} / \mathrm{L} \text { during } \\
\text { 6-month treatment period }\end{array}$ \\
\hline AVA-305 $[27,28]$ & $\begin{array}{l}\text { Phase } 3, \mathrm{MC} \text {, } \\
\mathrm{DB}, \mathrm{RCT}, \\
72 \text { centers in } \\
10 \text { countries }\end{array}$ & $\begin{array}{l}\text { AVA } \\
\qquad(n=12) \text { vs } \\
\text { ELT } \\
(n=11)\end{array}$ & $\begin{array}{l}20 \mathrm{mg} \\
\text { QD vs } \\
50 \mathrm{mg} \\
\text { QD }\end{array}$ & $\begin{array}{l}\text { Terminated early } \\
\text { because of poor } \\
\text { accrual }\end{array}$ & $\begin{array}{l}\text { Change from baseline in local } \\
\text { PC for the 6-month } \\
\text { treatment period }\end{array}$ \\
\hline RAISE [23] & $\begin{array}{l}\text { Phase } 3, \mathrm{MC}, \\
\mathrm{DB}, \mathrm{RCT}, \\
75 \text { centers in } \\
23 \text { countries }\end{array}$ & $\begin{array}{l}\text { ELT } \\
\qquad(n=135) \\
\text { vs PLC } \\
(n=62)\end{array}$ & $\begin{array}{r}50 \mathrm{mg} \\
\mathrm{QD}\end{array}$ & $\begin{array}{l}30(26 \\
\text { intervention }+4 \\
\text { follow-up) }\end{array}$ & $\begin{array}{l}\text { Percentage of responders [time } \\
\text { frame: Baseline; each on- } \\
\text { therapy treatment day; weeks } \\
\text { 10,14, 18, 22, and 26; and } \\
\text { weeks } 1,2 \text {, and } 4 \text { post } \\
\text { treatment] }\end{array}$ \\
\hline $\begin{array}{l}\text { NCT00102323 } \\
\text { (splenectomized } \\
\text { patients) }[24]\end{array}$ & $\begin{array}{l}\text { Phase } 3, \mathrm{MC} \text {, } \\
\mathrm{DB}, \mathrm{RCT}, \\
35 \text { sites in } \\
\text { the USA and }\end{array}$ & 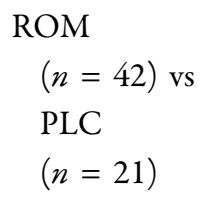 & $1 \mu \mathrm{g} / \mathrm{kg}$ & $\begin{array}{l}36(24 \\
\quad \text { intervention }+12 \\
\text { follow-up) }\end{array}$ & $\begin{array}{l}\text { Durable platelet response } \\
\text { during the last } 8 \text { weeks of } \\
\text { treatment and other platelet } \\
\text { response parameters }\end{array}$ \\
\hline $\begin{array}{l}\text { NCT00102336 } \\
\text { (non- } \\
\text { splenectomized } \\
\text { patients) }[24]\end{array}$ & Europe & $\begin{array}{l}\text { ROM } \\
\qquad(n=41) \text { vs } \\
\text { PLC } \\
(n=21)\end{array}$ & & & \\
\hline $\begin{array}{l}\text { FIT } 1[26] \\
\text { FIT } 2[26]\end{array}$ & $\begin{array}{c}\text { Phase 3, MC, } \\
\text { DB, RCT }\end{array}$ & $\begin{array}{l}\text { FOS } \\
\qquad \begin{array}{l}(n=51) \text { vs } \\
\text { PLC } \\
(n=25)\end{array}\end{array}$ & $\begin{array}{c}100 \mathrm{mg} \\
\text { BID }\end{array}$ & 24 & $\begin{array}{l}\text { Stable response (response } \\
\text { on } \geq 4 \text { of the last } 6 \text { visits } \\
\text { between weeks } 14 \text { and } 24 \text { ) }\end{array}$ \\
\hline
\end{tabular}

$A V A$ avatrombopag, $B I D$ twice a day, ELT eltrombopag, $D B$ double-blind, $F O S$ fostamatinib, $M C$ multicenter, $P C$ platelet count, $P L C$ placebo, $Q D$ once a day, $R O M$ romiplostim, $R C T$ randomized controlled trial

provided a direct connection between active treatments (Fig. 2).

\section{Feasibility Analysis and Heterogeneity}

Data were available allowing a comparison of the following outcomes for all treatments: durable platelet response; need for rescue treatment; WHO grade 2-4 bleeding events. Data for reduction in the use of concomitant ITP therapies were not available for fostamatinib.

The reporting of data from tests relating to liver functioning was described across all studies included in the NMA except for those involving romiplostim-the available data were heterogeneous, and there were very few observed events. Consequently, this confounded a reliable network comparison of hepatotoxicity. 


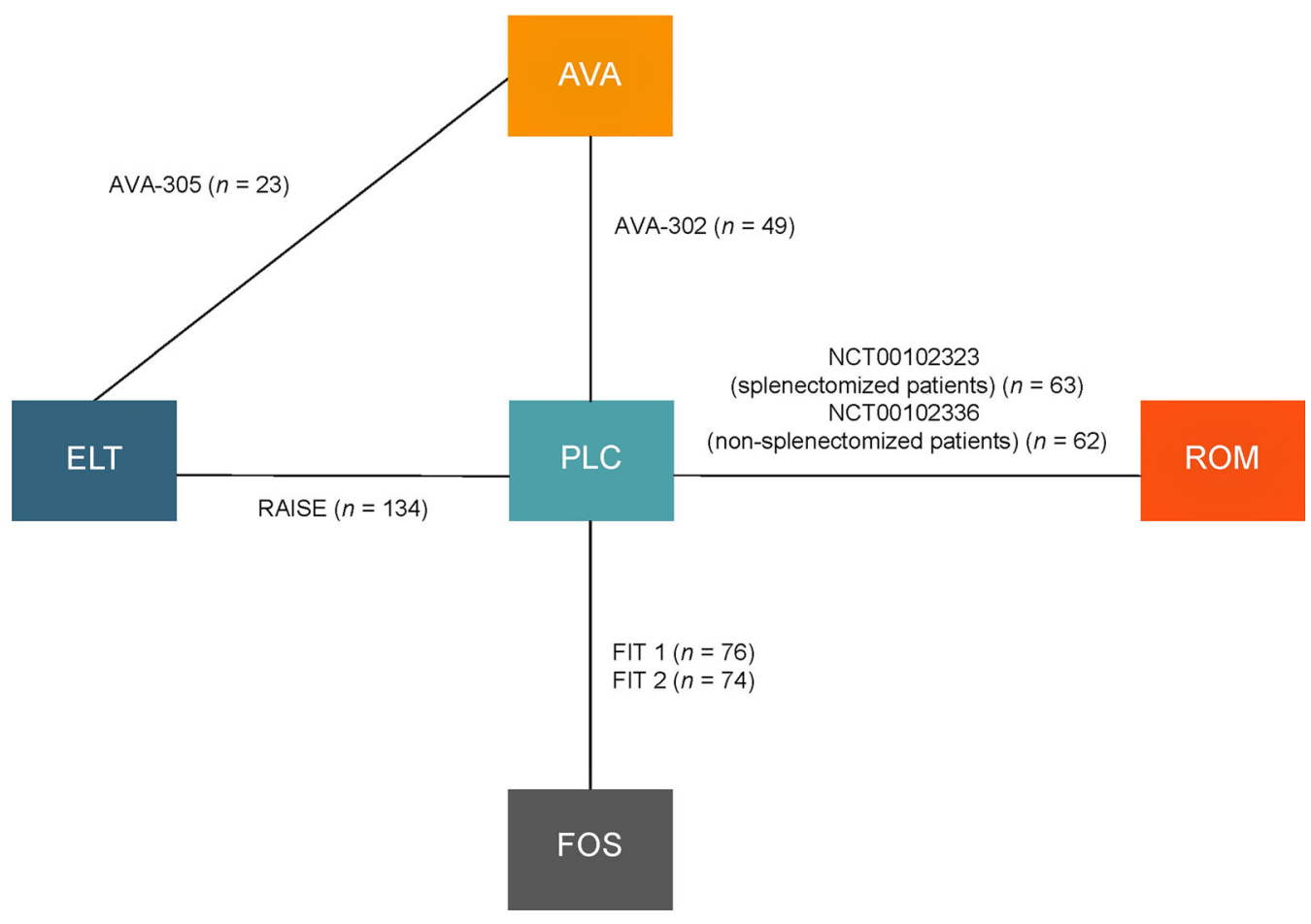

Fig. 2 Hypothetical network of evidence linking the studies included in the NMA. AVA avatrombopag, ELT eltrombopag, FOS fostamatinib, PLC placebo, ROM romiplostim

However, a summary of the hepatotoxicity data showed that eltrombopag is associated with elevated alanine aminotransferase and bilirubin (Table 3).

The definitions of durable response were relatively similar for all the treatments to allow comparison, although the definition was different in FIT 1 and FIT 2 (four of six visits over weeks 14-24) compared with the other trials (at least six of the last 8 weeks of treatment) (Table S3 in the supplementary material). In order to compare bleeding events among all treatments, it was assumed that WHO grade 2-4 bleeds are equivalent to grade 2-5 bleeds reported in Kuter [24] and moderate-severe bleeds reported in FIT 1 and FIT 2 trials [27].

\section{Clinical Efficacy}

Durable platelet response was reported in six studies (total of 458 patients). Input data for the NMA are shown in Table S4 in the supplementary material; data for eltrombopag were based on a post hoc analysis in only those patients with available platelet counts (95 out of 135 patients). Avatrombopag (OR 102.80 [95\% CrI 3.87, not estimable]), eltrombopag (OR 14.27 [95\% CrI 5.14, 53.73]), romiplostim (OR 46.49 [95\% CrI 9.12, 670.61]), and fostamatinib (OR 10.94 [95\% CrI 2.13, 181.70]) were associated with a statistically significant increased durable platelet response compared with placebo (Fig. 3a; Table S5). The point estimates vs the comparator agents were in favor of avatrombopag, although the relative estimates were imprecise because of very low event rates in the placebo groups. The cumulative probability of being the best treatment for this outcome was $82 \%$ for avatrombopag and $44-77 \%$ for the other agents.

Reduction in use of concomitant ITP medication was reported in four studies (total of 155 patients). Input data for the NMA are shown in Table S6 in the supplementary material. Avatrombopag (OR 48.75 [95\% CrI 1.34, not estimable]), eltrombopag (OR 3.08 [95\% CrI $1.25,7.98]$ ), and romiplostim (OR 13.72 [95\% CrI 2.84, 88.83]) were associated with a statistically significant reduced need for use of 
Table 3 Outcomes related to hepatoxicity as reported in five of the seven trials included in the network meta-analysis

\begin{tabular}{llll}
\hline Study & Definition & Treatment & Event rate \\
\hline AVA-302 [2] & Clinically meaningful elevation of liver enzymes (grade $\geq 3)$ & AVA & 1 event in 32 patients \\
& & PLC & 0 events \\
AVA-305 [27, 28] & Clinically meaningful elevation of liver enzymes (grade $\geq 3)$ & AVA & 1 event in 12 patients \\
& & ELT & 0 events in 11 patients \\
RAISE [23] & ALT $\geq 3 \times$ ULN & ELT & 9 events in 135 patients \\
& & PLC & 2 events in 61 patients \\
& Total bilirubin $>1.5 \times$ ULN & ELT & 5 events in 135 patients \\
& & PLC & 0 events in 61 patients \\
FIT 1 [26] & Severe ALT increased & FOS & 0 events in 102 patients \\
& & PLC & 0 events in 48 patients \\
FIT 2 [26] & Severe AST increased & FOS & 0 events in 102 patients \\
& & PLC & 0 events in 48 patients \\
\hline
\end{tabular}

No such information was provided for the studies involving ROM Kuter et al. [24]

$A L T$ alanine aminotransferase, $A V A$ avatrombopag, ELT eltrombopag, FOS fostamatinib, PLC placebo, ROM romiplostim, $U L N$ upper limit of normal

concomitant medication compared with placebo (Fig. 3b; Table S7 in the supplementary material). There was no evidence of statistically significant differences between the active treatments. The cumulative probability of being the best treatment for this outcome was highest for avatrombopag (86\%) and romiplostim (75\%).

Need for rescue therapy was assessed in six studies (total of 521 patients). Input data for the NMA are shown in Table S8 in the supplementary material. All treatments demonstrated superiority vs placebo (eltrombopag, IRR 0.46 [95\% CrI 0.26, 0.79]; romiplostim, IRR 0.35 [95\% CrI 0.19, 0.64]; fostamatinib, IRR 0.37 [95\% CrI 0.21, 0.65]) except avatrombopag for which the difference was not significant (Fig. 3c; Table S9 in the supplementary material). There was no evidence of statistically significant differences between avatrombopag and the other agents. The cumulative probability of being the best treatment for this outcome was highest for romiplostim (78\%) and fostamatinib (73\%).
Incidence of any bleeding events was based on seven studies (total of 545 patients). Input data for the NMA are shown in Table S10 in the supplementary material. Avatrombopag (IRR 0.34 [95\% CrI 0.18, 0.66]) and fostamatinib (IRR 0.50 [95\% CrI 0.27, 0.91]) were associated with a statistically significant lower incidence of any bleeding events compared with placebo (Fig. 3d; Table S11 in the supplementary material). Additionally, avatrombopag was associated with a statistically significant lower incidence of any bleed vs eltrombopag (IRR 0.38 [95\% CrI $0.19,0.75]$ ) and romiplostim (IRR 0.38 [95\% CrI $0.17,0.86])$. Avatrombopag was associated with the highest cumulative probability of being the best treatment (99\%) for this outcome vs fostamatinib (77\%), eltrombopag (33\%), and romiplostim (31\%). There was no evidence for inconsistency in the results within the closed evidence loop formed by avatrombopag, eltrombopag, and placebo (direct IRR for avatrombopag vs placebo $=0.32 \quad[95 \%$ CrI 0.14 , 0.75]; indirect IRR for avatrombopag vs 
placebo $=0.46 \quad[95 \%$ CrI $0.16,1.33] ; p$ for heterogeneity $=0.60$ ).

Incidence of WHO grade $2-4$ bleeding events was reported for six studies (recruiting a total of 545 patients). Input data for the NMA are shown in Table S12 in the supplementary material. No statistically significant differences were observed for avatrombopag compared with placebo or any of the other agents (Fig. 3e; Table S13 in the supplementary material). Statistically significant differences were observed for romiplostim (IRR 0.44 [95\% CrI 0.20, 0.93]) and fostamatinib (IRR 0.38 [95\% CrI 0.15, 0.95]) vs placebo. The cumulative probability of being the best treatment for this outcome was similar for the treatments (range 40-76\%). There was no evidence for inconsistency in the results within the closed evidence loop formed by avatrombopag, eltrombopag, and placebo (direct IRR for avatrombopag vs placebo $=4.63$ [95\% CrI 0.04, 575.58]; indirect IRR for avatrombopag vs placebo $=0.95[95 \%$ CrI 0.17 , 5.22]; $p$ for heterogeneity $=0.54$ ).

\section{Safety Profile}

The incidence of any AEs was based on five studies (recruiting a total of 542 patients). Input data for the NMA are shown in Table S14 in the supplementary material. No statistically significant differences were observed for avatrombopag or the other agents compared with placebo (Fig. 3f; Table S15 in the supplementary material). Similarly, no statistically significant between-treatment differences were detected. Avatrombopag (85\%) and fostamatinib (80\%) had the highest cumulative probabilities of being the best treatment. There was no evidence for inconsistency of the results within the closed evidence loop formed by avatrombopag, eltrombopag, and placebo (direct IRR for avatrombopag vs placebo $=0.65[95 \%$ CrI 0.32 , 1.32]; indirect IRR for avatrombopag vs placebo $=0.63 \quad[95 \%$ CrI $0.26,1.54] ; p$ for heterogeneity $=0.96$ ).

\section{DISCUSSION}

The results of the NMA indicate that in patients with cITP and an insufficient response to previous treatment, avatrombopag provides a statistically significant efficacy benefit compared with placebo for the following outcomes: improved durable platelet response, reduced use of concomitant ITP medication, and decreased risk of any bleeding events. The comparative analysis revealed a statistically significant lower estimated incidence of any bleeding events for avatrombopag compared with eltrombopag and romiplostim; no other between-treatment differences were observed. This analysis, which is based on the best available clinical data, adds to the limited evidence base for this condition and may ultimately help to guide clinicians managing patients with cITP.

Of the studies included in the NMA, only those for avatrombopag [22, 28, 29] applied most recent definition of cITP (i.e., at least 12 months' duration) [5]. The relaxation of inclusion criteria for the duration of cITP to enable evaluation of other drugs may have reduced the stringency required for evaluation of clinical evidence in these comparators and therefore it is possible that the efficacy estimates for avatrombopag could be somewhat conservative.

No significant differences in any AEs were observed between treatments, likely because neither of the avatrombopag studies were adequately powered to assess safety. Comparisons of hepatoxicity could not be performed because of limited data; however, eltrombopag appears to be associated with abnormal tests relating to liver functioning and has a risk of severe and potentially life-threatening hepatotoxicity $[9,30]$. Similarly, a comparative analysis was not feasible for mortality or serious AEs because of low sample sizes, short trial/follow-up durations, inadequate power, and low number of events.

The efficacy and safety data inputs used in this NMA were determined using relative effect sizes for the active treatment vs placebo, with larger values indicating greater benefit of the treatment. For some key outcomes, notably durable platelet response and reduction in the use of concomitant medication, there were very few or zero events observed in placebo groups, leading to difficulties in the estimation of relative effects and the subsequent broad upper 

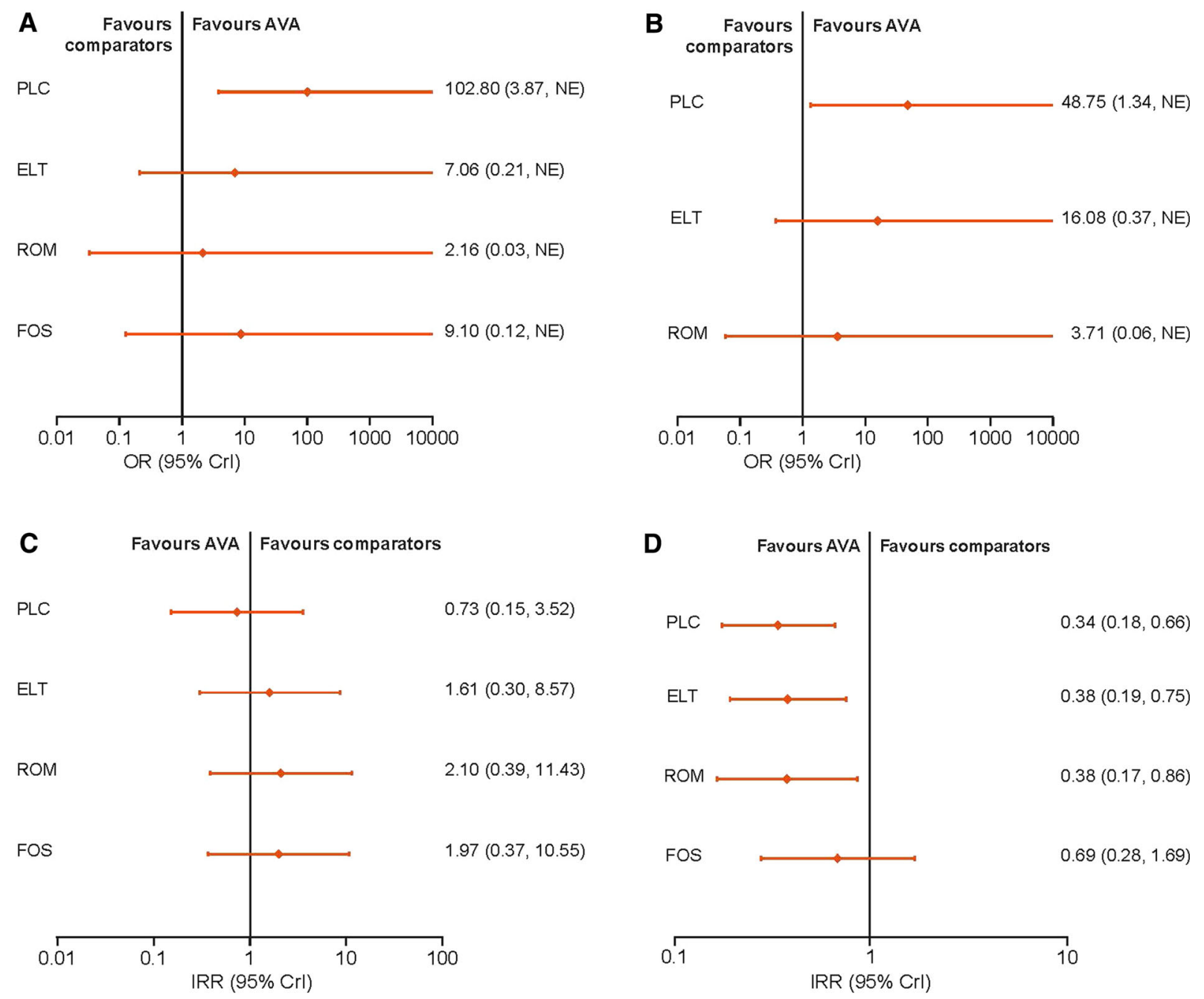

\begin{tabular}{ll|l} 
D $\quad$ Favours AVA & Favours comparators
\end{tabular}
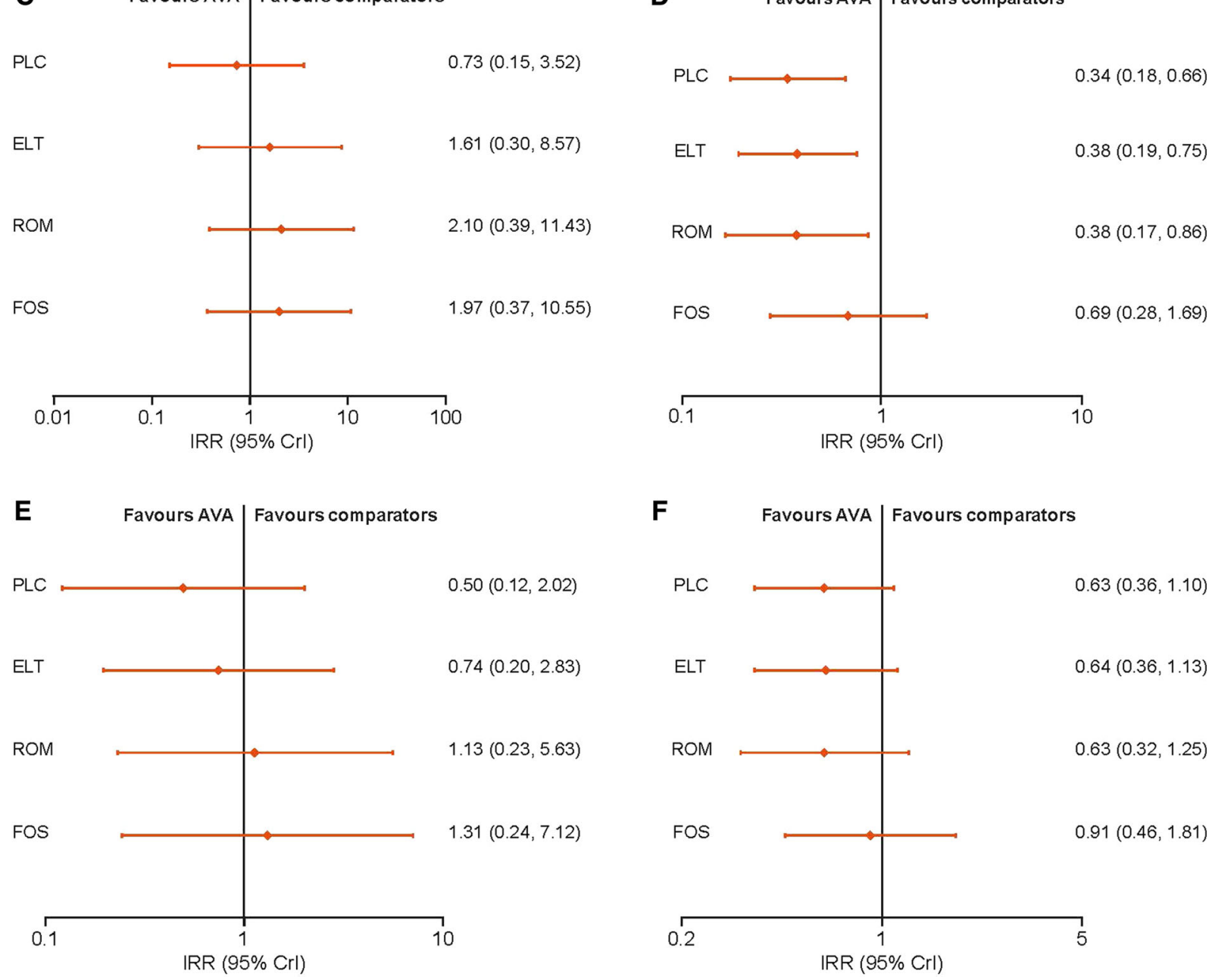
4Fig. 3 Forest plots for a durable platelet response; b reduction in the use of concomitant ITP medication; c need for rescue therapy; $\mathbf{d}$ incidence of any bleeding events; e incidence of WHO grade 2-4 bleeding events; f any adverse event. Fixed-effect model for all outcomes. AVA avatrombopag, ELT eltrombopag, CrI credible interval, FOS fostamatinib, IRR incidence rate ratio, NE not estimable, OR odds ratio, PLC placebo, ROM romiplostim, WHO World Health Organization

credible intervals. Nevertheless, the estimates from the NMA consistently indicated superiority of active treatments over placebo. All the studies had limited sample sizes, likely confounded by the rarity of disease and other factors. The definitions for durable response and severe bleeds were inconsistent across studies but were considered comparable enough for the analysis. Key outcomes were not pre-specified in all studies, and may have been assessed retrospectively using available data, e.g., for durable platelet response in the eltrombopag RAISE trial [23].

Splenectomy and rituximab are other proposed treatment options for cITP in addition to the TPO-RAs and fostamatinib. Splenectomy, the prior gold standard treatment for severe cITP and now largely used as a third-line treatment option in clinical practice, provides response rates of $60 \%$ to $80 \%$ and remission in up to two-thirds of patients [3]. As a result of a lack of RCTs, rituximab is used off-label for cITP. Rituximab may be used prior to or after TPORAs or splenectomy; it appears to provide good response rates, although they may be shortlasting in approximately $80 \%$ of patients, and it may be reserved for patients with a high bleeding risk [3, 4]. AEs with rituximab include pruritus, urticaria, serum sickness, and cardiac arrhythmias.

Three other NMAs comparing therapeutic options in adult patients with cITP have been published [31-33]. In contrast to the present study, Arai et al. and Puavilai et al. included studies published up to 2016 and 2018, respectively, and only considered those reporting eltrombopag and romiplostim plus rituximab (not approved for treatment of ITP). Yang et al. included a wider spectrum of therapies, including avatrombopag and fostamatinib, and similar to our analysis avatrombopag was shown to produce more satisfactory outcomes than romiplostim and eltrombopag (in addition to rituximab) in terms of early response (defined as a platelet count of at least $50 \times 10^{9} / \mathrm{L}$ at 2 weeks after treatment initiation), while ranking second (SUCRA) for overall response (defined as a platelet count of at least $50 \times 10^{9} / \mathrm{L}$ at the end of treatment without rescue therapy). In contrast to the NMA we describe, the trials included in the comparisons reported by Yang et al. [33] included the phase 2 study only for avatrombopag [34], some studies performed exclusively in China and Japan, and there was no requirement for patients to have cITP.

Several aspects that may impact treatment selection, drug adherence, and/or patient acceptability [6] could not be captured in this NMA. Eltrombopag should be initiated at a reduced dose in adult patients of Asian ancestry or those with hepatic impairment [9], requires regular monitoring for clinical hematology and liver function, and has some dietary restrictions [35]. In contrast to the oral therapies, romiplostim must be administered by subcutaneous injection [11]. Blood pressure should be monitored regularly in patients receiving fostamatinib owing to an increased risk of hypertension [12]. Avatrombopag can be administered without regular monitoring and dose adjustment for food types or side effects, and is not contraindicated in patients with moderate or severe hepatic impairment [10].

In AVA-302 [22], the imbalance in discontinuation rates between the active and placebo groups (31\% and 94\%, respectively) was largely driven by a suboptimal response to therapy ( $22 \%$ vs $88 \%$, respectively), suggesting that avatrombopag was more effective than placebo. In contrast, the proportion of patients who prematurely discontinued fostamatinib therapy (75\% overall; $60 \%$ due to suboptimal response) was more than twofold higher than those observed with avatrombopag and much closer to the rate of discontinuation for the corresponding placebo group in study AVA-302 [27]. The rate of early discontinuation was much lower in trials assessing eltrombopag [23] and romiplostim [24], which can be explained by 
the fact that participants of these early studies had limited treatment alternatives. In this NMA, adjustment for imbalances in early discontinuation was accounted for through required estimation of event rates based on binary data and assumed that a single patient could experience only one event of the same kind. We recognize that this may not be true, especially for safety outcomes, but the same approach was consistently adopted for all studies and this approach is likely more robust than comparing crude binary data which are highly likely biased because of large and imbalanced discontinuation.

The limitations regarding the rate of discontinuation in the trials and the lack of RCTs for comparators meeting all inclusion criteria have been described in the "Methods" section. A further limitation is the small sample sizes of the studies assessing avatrombopag, which limits the amount of clinical data available for avatrombopag; therefore, this NMA may be underpowered to demonstrate a significant between-treatment differences regarding clinical outcomes.

\section{CONCLUSIONS}

This NMA of treatment efficacy and safety in adult patients with cITP and insufficient response to previous therapy found that avatrombopag was associated with a greater chance of durable response, reduced use of concomitant ITP treatments, and less frequent bleeding events than placebo. In addition, avatrombopag may be associated with a reduced rate of any bleeding event when compared with eltrombopag and romiplostim. No significant differences in rates of any AEs were observed across the treatments, but avatrombopag has no serious safety warnings.

\section{ACKNOWLEDGEMENTS}

Funding. This research was funded by Swedish Orphan Biovitrum AB (Sobi) and implemented by an independent consultancy,
Creativ-Ceutical, which performed the systematic literature search and network meta-analysis. The journal open access fee was funded by Sobi.

Authorship. All named authors meet the International Committee of Medical Journal Editors (ICMJE) criteria for authorship for this article, take responsibility for the integrity of the work as a whole, and have given their approval for this version to be published.

Authorship Contributions. Piotr Wojciechowski, Iwona Pustulka, Anna Tytula, Beata Smela and Michał Pochopien designed and conducted the analysis. All authors contributed to data analysis, drafting or revising the article, and have agreed on the journal to which the article will be submitted.

Medical Writing, Editorial, and Other Assistance. Medical writing and editorial support, funded by Sobi, Stockholm, Sweden, was provided by Andy Lockley and Tyrone Daniel of Bioscript Medical, Macclesfield, UK.

Disclosures. Piotr Wojciechowski, Iwona Pustulka, Anna Tytula, Beata Smela and Michał Pochopien are employees of Creativ-Ceutical, which was contracted by Sobi to design and conduct this analysis; Koo Wilson and Jameel Nazir are employees of Sobi and the former holds company shares; Michael Vredenburg is an employee of Dova Pharmaceuticals, a subsidiary of Sobi; Keith R. McCrae reports personal fees from Novartis and Dova; Wojciech Jurczak reports grants from Eisai and advisory board attendance for Sobi.

Compliance with Ethics Guidelines. This article is based on previously conducted studies and did not require any new experiments with human participants or animals.

Data Availability. This is a meta-analysis that used published data from clinical trials. Data are provided in the supplemental tables.

Open Access. This article is licensed under a Creative Commons Attribution- 
NonCommercial 4.0 International License, which permits any non-commercial use, sharing, adaptation, distribution and reproduction in any medium or format, as long as you give appropriate credit to the original author(s) and the source, provide a link to the Creative Commons licence, and indicate if changes were made. The images or other third party material in this article are included in the article's Creative Commons licence, unless indicated otherwise in a credit line to the material. If material is not included in the article's Creative Commons licence and your intended use is not permitted by statutory regulation or exceeds the permitted use, you will need to obtain permission directly from the copyright holder. To view a copy of this licence, visit http:// creativecommons.org/licenses/by-nc/4.0/.

\section{REFERENCES}

1. Nugent D, McMillan R, Nichol JL, Slichter SJ. Pathogenesis of chronic immune thrombocytopenia: increased platelet destruction and/or decreased platelet production. Br J Haematol. 2009;146(6): 585-96.

2. Rodeghiero F. Is ITP a thrombophilic disorder? Am J Hematol. 2016;91(1):39-45.

3. Khan AM, Mydra H, Nevarez A. Clinical practice updates in the management of immune thrombocytopenia. P T. 2017;42(12):756-63.

4. Kistangari G, McCrae KR. Immune thrombocytopenia. Hematol Oncol Clin North Am. 2013;27(3):495-520.

5. Rodeghiero F, Stasi R, Gernsheimer T, et al. Standardization of terminology, definitions and outcome criteria in immune thrombocytopenic purpura of adults and children: report from an international working group. Blood. 2009;113(11): 2386-93.

6. Neunert C, Terrell DR, Arnold DM, et al. American Society of Hematology 2019 guidelines for immune thrombocytopenia. Blood Adv. 2019;3(23): 3829-66.

7. Provan D, Arnold DM, Bussel JB, et al. Updated international consensus report on the investigation and management of primary immune thrombocytopenia. Blood Adv. 2019;3(22):3780-817.
8. National Organization for Rare Disorders. Rare disease database. Immune thrombocytopenia. 2020. https://rarediseases.org/rare-diseases/immunethrombocytopenia/. Accessed Nov 2020.

9. EMC. Revolade (eltrombopag olamine) Summary of Product Characteristics. 2020. https://www. medicines.org.uk/emc/product/508/smpc. Accessed Dec 2020.

10. Swedish Orphan Biovitrum AB (publ). Doptelet Summary of Product Characteristics. 2020. https:// www.ema.europa.eu/en/documents/productinformation/doptelet-epar-product-information en.pdf. Accessed Nov 2020.

11. Amgen Europe B.V. Nplate Summary of Product Characteristics. 2020. https://www.ema.europa.eu/ en/documents/product-information/nplate-eparproduct-information_en.pdf. Accessed Nov 2020.

12. Instituto Grifols SA. Tavlesse Summary of Product Characteristics. 2020. https://www.ema.europa.eu/ en/documents/product-information/tavlesse-eparproduct-information_en.pdf. Accessed Nov 2020.

13. Gonzalez-Porras JR, Godeau B, Carpenedo M. Switching thrombopoietin receptor agonist treatments in patients with primary immune thrombocytopenia. Ther Adv Hematol. 2019;10: 2040620719837906.

14. Chaturvedi S, Arnold DM, McCrae KR. Splenectomy for immune thrombocytopenia: down but not out. Blood. 2018;131(11):1172-82.

15. Sarpatwari A, Bennett D, Logie JW, et al. Thromboembolic events among adult patients with primary immune thrombocytopenia in the United Kingdom General Practice Research Database. Haematologica. 2010;95(7):1167-75.

16. Dova Pharmaceuticals. DOPTELET prescribing information. 2020. https://dova.com/wp-content/ uploads/2019/06/doptelet-prescribing-information. pdf. Accessed Jan 2021.

17. Hutton B, Salanti G, Caldwell DM, et al. The PRISMA extension statement for reporting of systematic reviews incorporating network meta-analyses of health care interventions: checklist and explanations. Ann Intern Med. 2015;162(11): 777-84.

18. Boyers D, Jia X, Jenkinson D, Mowatt G. Eltrombopag for the treatment of chronic immune or idiopathic thrombocytopenic purpura: a NICE single technology appraisal. Pharmacoeconomics. 2012;30(6):483-95.

19. Mowatt G, Boachie C, Crowther M, et al. Romiplostim for the treatment of chronic immune or 
idiopathic thrombocytopenic purpura: a single technology appraisal. Health Technol Assess. 2009;13(Suppl 2):63-8.

20. The Cochrane Collaboration. Cochrane handbook for systematic reviews of interventions. In: Higgins J, Green S, editors. Part 2: General methods for Cochrane reviews. 6 Searching for studies; 6.4 Designing search strategies. 2011. https:// handbook-5-1.cochrane.org/chapter_6/6_4_ designing_search_strategies.htm.

21. Centre for Reviews and Dissemination. Systematic reviews. CRD's guidance for undertaking reviews in health care. 2009. https://www.york.ac.uk/media/ crd/Systematic_Reviews.pdf. Accessed Dec 2020.

22. Jurczak W, Chojnowski K, Mayer J, et al. Phase 3 randomised study of avatrombopag, a novel thrombopoietin receptor agonist for the treatment of chronic immune thrombocytopenia. Br J Haematol. 2018;183(3):479-90.

23. Cheng G, Saleh MN, Marcher C, et al. Eltrombopag for management of chronic immune thrombocytopenia (RAISE): a 6-month, randomised, phase 3 study. Lancet. 2011;377(9763):393-402.

24. Kuter DJ, Bussel JB, Lyons RM, et al. Efficacy of romiplostim in patients with chronic immune thrombocytopenic purpura: a double-blind randomised controlled trial. Lancet. 2008;371(9610): 395-403.

25. Dias S, Welton NJ, Sutton AJ, Ades AE. NICE DSU technical support document 2: a generalised linear modelling framework for pairwise and network meta-analysis of randomised controlled trials. 2011; last updated September 2016. http://www.nicedsu. org.uk. Accessed Dec 2020.

26. NICE Decision Support Unit. NICE DSU TECHNICAL SUPPORT DOCUMENT 4. Inconsistency in networks of evidence based on randomised controlled trials. 2011. http://nicedsu.org.uk/wpcontent/uploads/2016/03/TSD4-Inconsistency. final_.15April2014.pdf. Acessed Mar 2021.

27. Bussel J, Arnold DM, Grossbard E, et al. Fostamatinib for the treatment of adult persistent and chronic immune thrombocytopenia: results of two phase 3, randomized, placebo-controlled trials. Am J Hematol. 2018;93(7):921-30.

28. ClinicalTrials.gov. A phase 3, multicenter, randomized, double-blind, active-controlled, parallelgroup trial with an open-label extension phase to evaluate the efficacy and safety of oral E5501 vs eltrombopag, in adults with chronic immune thrombocytopenia idiopathic thrombocytopenic purpura). Updated 2018. https://clinicaltrials.gov/ ct2/show/study/NCT01433978. Accessed Nov 2020.

29. Tarantino M, Vredenberg M, Tian W, Jamieson B, Patel KB. Efficacy analyses from the immune thrombocytopenia (ITP) clinical development program for avatrombopag: comparisons with placebo and eltrombopag. Blood. 2020;136(Suppl. 1):23-4.

30. FDA. PROMACTA ${ }^{\circledR}$ (eltrombopag) Highlights of Prescribing Information. 2020. https:/www. accessdata.fda.gov/drugsatfda_docs/label/2020/ 022291s027,207027s010lbl.pdf. Accessed Dec 2020.

31. Arai Y, Matsui H, Jo T, Kondo T, Takaori-Kondo A. Comparison of treatments for persistent/chronic immune thrombocytopenia: a systematic review and network meta-analysis. Platelets. 2019;30(8): 946-56.

32. Puavilai T, Thadanipon K, Rattanasiri S, et al. Treatment efficacy for adult persistent immune thrombocytopenia: a systematic review and network metaanalysis. Br J Haematol. 2020;188(3):450-9.

33. Yang R, Lin L, Yao H, Ji O, Shen Q. Therapeutic options for adult patients with previously treated immune thrombocytopenia - a systematic review and network meta-analysis. Hematology. 2019;24(1):290-9.

34. Bussel JB, Kuter DJ, Aledort LM, et al. A randomized trial of avatrombopag, an investigational thrombopoietin-receptor agonist, in persistent and chronic immune thrombocytopenia. Blood. 2014;123(25):3887-94.

35. Williams DD, Peng B, Bailey CK, et al. Effects of food and antacids on the pharmacokinetics of eltrombopag in healthy adult subjects: two singledose, open-label, randomized-sequence, crossover studies. Clin Ther. 2009;31(4):764-76. 